\title{
$\Omega$
}

Cristina Braço Forte', Susana Sousa ${ }^{1,2,3}$

D

1Pneumology, Centro Hospitalar de Setubal EPE, Setubal, Portugal.

Infante Santo CUF Hospital, Lisbon, Portugal.

${ }^{3}$ Nova Medical School, Universidade Nova de Lisboa Faculdade de Ciencias Medicas, Lisbon, Portugal.

\section{End of life in COPD patients: time for a change}

Despite being the fourth leading cause of death worldwide and being associated with a high morbidity, most patients with chronic obstructive pulmonary diseases (COPD) do not receive adequate treatment in the terminal stage of the disease. Doctor-patient communication about end-of-life decisions and palliative care is rare, and there are no reliable tools to identify the patients with poorer prognosis to whom special measures should be applied. A clear discussion of the subject is urgently needed in order that informed decisions are made jointly by the doctor, patient and family.

COPD is a progressive disease and, in many cases, the clinical deterioration and symptomatic aggravation lead to end-stage disease. One of the main problems that prevent proper care at the end of life of COPD patients is the difficulty of defining the final stage of the disease. There are numerous consensuses on COPD treatment that include recommendations for diagnosis, classification of severity and therapeutic guidelines. Bioethical considerations of end-stage disease are often missing or are dealt with superficially. Some studies comparing the quality of life of cancer patients and patients with severe COPD have showed that the latter have a worse quality of life [1]. Palliative care is directed primarily toward cancer patients and their family, and is not addressed for patients with nonneoplastic diseases. Data also show that patients with COPD have higher anxiety and depression rates, and a more significant morbidity than patients with lung cancer. The end of life of patients with COPD is associated with progressive deterioration, a worse quality of life, social isolation and absence of symptom control. The main barriers to a correct and appropriate approach at this stage of the disease are: lack of resources, deficient identification of patients at the end stage and absence of robust studies in the area.

Some scientific societies have listed indicators associated with lower survival (survival $<12$ months), including dyspnoea class, functional respiratory testing, exercise tolerance, past hospitalisations, comorbid diseases and age [2, 3].

Once the patient is identified, decisions must be made before exacerbations, in order to avoid that other health professionals, who do not know the patient and their decisions, have to deal with the dilemmas surrounding the final stages of life. A large-scale study has shown that the majority of patients who die in intensive care units are subjected to invasive treatment measures against their previous desires [4].

End-of-life decisions must be made on an individual basis, within a social, cultural and family context, and in accordance with religious beliefs. Recommendations on this topic should follow this principle and should always be personalised. It is essential to understand that the decisions of the patient are not irrevocable and can be changed at any moment in the process. An algorithm for the care of end-of-life COPD patients including three stages has recently been proposed [2].

The first stage addresses the diagnosis and classification of severity, in order to identify the patient, and obtain information on their situation and family context. Following that, a process of dialogue and education about the disease, the therapeutic
Cite as: Braço Forte $\mathrm{C}$, Sousa S. End of life in COPD patients: time for a change. Breathe 2017; 13: e84-e86. 
alternatives and the possibility of palliative care should be initiated. Communication is the key to all discussion. The patient's decision must be an informed decision and it should be explained to them that the decision not to resuscitate does not mean nontreatment. The decision should be the result of a sharing process between doctor, patient and family. Some studies show that only a third of COPD patients under long-term oxygen therapy talk with their physician about end-of-life decisions and $<25 \%$ of the doctors discuss this with their patients [5]. When patients are questioned about the need for information, most of them are curious about the diagnosis, outcome, treatment, prognosis and planning strategy for the end of life [5]. Another study involving 105 COPD patients in a rehabilitation programme showed that $99 \%$ of the patients wanted their doctors to address the issue of end-of-life decisions and life support measures, but only $19 \%$ had received this information [6]. Many patients also express a desire to discuss their religious and spiritual beliefs with their doctors. The religious beliefs and cultural differences of patients and their families have a profound influence on decision-making, the attitude towards death and the discussion of the subject. Some patients believe that suffering corresponds to a test of faith and that only God has the power to decide on the moment of death, which can affect the way these patients think about life support and palliative measures. Even in these cases it may be useful, for example, to refer to the Vatican declaration on euthanasia [7], which considers that when imminent death is inevitable the patient may consent to the use of opioid analgesia and sedation, as well as to refuse forms of treatment that will only prolong life in a precarious way and with inevitable deterioration. The doctor must have this capacity to listen to, communicate with, educate and clarify the understanding of the patient and their family.

The second stage corresponds to a period of regular assessment in order to monitor the progression of the disease, by using indicators such as those previously described, to identify patients with an estimated survival of less than 6-12 months. These indicators, which are a set of prognostic factors enumerated by the different scientific societies, allow the attending doctor to anticipate the final stage of the disease and to decide on how to act at that moment, in a gradual process and with the participation of the patient.

The third and last stage is the planning of advance decisions, which include, for example, the place where the patient wants to be treated, the treatment goals, the type of palliative care to be provided, and the psychological and/or spiritual care. Ideally, these advance decisions should be written. There is evidence that having an anticipatory therapeutic plan is beneficial to the patient, since it increases their satisfaction and feeling of control over the illness, and reduces anxiety, fear and emotional stress [8].

Although a seemingly simple strategy, there are still many barriers to the implementation of these programmes. The barrier related to end-of-life communication is bidirectional. If, on the one hand, health professionals find it difficult due to the lack of time during consultations, fear of compromising the hopes of the patient, difficulty in establishing a prognosis and the prejudice that patients do not wish to address this issue, on the other hand, there are also obstacles on the part of the patient. Most patients believe that this discussion should be initiated by the doctor, and there are taboos surrounding the topic of death and uncertainty about what kind of care the patient prefers at a later stage of the disease.

Following the principles of Elio Sgreccia's personalist ethics, "the patients (or someone on their behalf) who have become aware of their state of health and its limits, who recognize that they are not competent in the field of the disease that threatens them and diminishes their autonomy, in order to recover or prevent prejudice to their autonomy, take the initiative to address another person, the doctor, who, due to his/her preparation and experience of the profession, is able to help them. The patient remains as the leading actor in the provision of health. The doctor who agrees to help them is also an actor, but in the sense of one who collaborates with the main subject or for a particular purpose." [9]. Communication between the two "actors" is the critical point of the whole process in which the bond is key. However, not all doctors have this capacity or the knowledge of how to communicate effectively. Teaching health professionals about end-of-life decisions and the bioethical problems in the treatment of these patients, as well as the training to develop doctorpatient communication skills on the subject, are key steps to approach end-stage COPD properly.

COPD is a major cause of mortality and morbidity, and most patients progress to a stage of difficult symptom control and social isolation, with repercussions on their quality of life. Historically, palliative care programmes have been designed for cancer patients; however, all patients with progressive conditions should be included in these programmes. When indicators allow identification of a patient with COPD and an estimated survival of less than 6-12 months, it is recommended to plan end-of-life decisions. Communication between the doctor, patient and family is the key point in this procedure, which is designed to enable an informed, shared and mature decision that can be continuously updated throughout the process. 


\section{References}

1. The SUPPORT Principal investigators. A controlled trial to improve care for seriously ill hospitalized patients. The Study to Understand Prognoses and Preferences for Outcomes and Risks of Treatments. JAMA 1995; 274: 1591-1598.

2. Gil B. EPOC en la etapa final de la vida: recomendaciones de procedimiento [COPD in the final stage of life: procedure recommendations]. Rev Am Med Respir 2012; 12: 54-61.

3. Escarrabill J, Soler Cataluna J, Hernandez C, et al. Normativa SEPAR. Recomendaciones sobre la atencion al final de vida e pacientes con EPOC [Recommendations for end-of-life care in patients with chronic obstructive pulmonary disease]. Arch Bronchoneumol 2009; 45: 297-303.

4. Carlucci A, Guerrieri A, Nava S. Palliative care in COPD patients: is it only an end of life issue? Eur Respir Rev 2012; 21: 347-354
5. Curtis JR. Palliative and end-of-life care for patients with severe COPD. Eur Respir Rev 2008; 32: 796-803.

6. Heffner JE, Fahy B, Hilling L, et al. Outcomes of advance directive education of pulmonary rehabilitation patients. Am J Respir Crit Care Med 1997; 155: 1055-1059.

7. Sacred Congregation for the Doctrine of the Faith. Declaration on Euthanasia. www.vatican.va/roman_curia/ congregations/cfaith/documents/rc_con_cfaith_doc_ 19800505_euthanasia_en.html

8. Spathis A, Booth S. End of life care in chronic obstructive pulmonary disease: in search of a good death. Int J COPD 2008; 3: 11-29.

9. Sgreccia E. Manual de Bioética I: Fundamentos e Ética Biomedical. Madrid, Biblioteca de Autores Cristianos, 2009. 